\title{
Does primary stenting preserve cardiac function in myocardial infarction? A case-control study
}

\author{
H Sasao, K Tsuchihashi, M Hase, T Nakata, K Shimamoto, and the NORTH-981 \\ investigators
}

\begin{abstract}
Objective-To investigate whether coronary stenting limits myocardial injury and preserves left ventricular function.

Design and setting-Prospective multicentre case-control study of primary percutaneous transluminal coronary angioplasty (PTCA) with and without stenting, performed in seven cardiovascular centres.

Subjects and methods -45 consecutive patients with acute myocardial infarction who were treated with successful primary stenting (Stent group) and did not have restenosis were paired with 45 matched control subjects with acute myocardial infarction treated by successful primary PTCA without stenting, also with no restenosis (POBA group).

Results-In comparison with the POBA group, the Stent group-especially those patients with a left anterior descending coronary artery lesion-had a smaller hypokinesis area (mean (SD): $15.1(20.0) v 34.4$ (24.3) chords), reduced hypokinesis area/risk area $(25.2(31.9) \% v 58.8$ $(40.1) \%)$, and a larger ejection fraction $(63.3(10.2) \% v 51.7(11.7) \%)$ evaluated by quantitative left ventriculography using the centreline method. In the Stent group, the correlation between risk area and hypokinesis area was significantly shifted downward. Multiple logistic regression analysis on infarct size limitation (hypokinesis area/risk area $<50 \%$ ) identified preinfarction angina in all subjects and preinfarction angina and stenting in patients with left anterior descending coronary artery leasions as explanatory factors.

Conclusions-Primary PTCA using a coronary stent is effective in preventing myocardial injury and restoring left ventricular function in patients with anterior acute myocardial infarction.

(Heart 2000;84:515-521)
\end{abstract}

Keywords: acute myocardial infarction; primary stenting; left ventricular function; preinfarction angina

Early revascularisation in acute myocardial infarction by primary percutaneous transluminal coronary angioplasty (PTCA) has been shown to limit infarct size and improve the prognosis. ${ }^{1-10}$ However, the incidence of restenosis of the infarct related artery is estimated to be as high as $40-50 \%$, and the incidence of major adverse events related to recurrent ischaemia - such as death, reinfarction, and repeated target vessel revascularisation-has been reported to be as high as $30 \%$ in previous studies. ${ }^{8-10}$ Furthermore, postischaemic microvascular incompetence, possibly reflecting partial occlusion of the infarct related artery, distal embolism of platelet aggregates formed at dilated plaques, or microvascular reperfusion injury during early reperfusion period, may still compromise myocardial perfusion after revascularisation of the epicardial coronary arteries, and it has been suggested that this is a clinical limitation of primary PTCA. ${ }^{11} 12$

Though thrombus formation in the stent has been considered a theoretical risk in elective coronary stent placement, ${ }^{13}$ unplanned stenting of the infarct related artery in cases with suboptimal or poor angiographic coronary flow has been reported to be a safe and feasible treatment option, with a good clinical outcome associated with a reduced rate of restenosis and related major adverse events. ${ }^{14-16}$ Prospective randomised trials of primary stenting in acute myocardial infarction have shown a reduced incidence of cardiac events associated with recurrent ischaemia, and a lessening of angiographic restenosis or occlusion of the infarct related artery. ${ }^{17-19}$

A recent coronary blood flow study of elective PTCA in stable angina, using intravascular ultrasound imaging and a Doppler guide wire, ${ }^{20}$ has shown that the coronary vasodilator reserve is significantly increased after stenting, independently of the angiographic outcome. Thus primary stenting of the infarct related artery might have a beneficial effect not only in preserving the coronary vasodilator reserve but also in preventing myocardial injury, restoring left ventricular function, and preventing heart failure in the postinfarction period.

To test the effects of primary stenting on the prevention of myocardial injury and the restoration of left ventricular function in acute myocardial infarction, we performed a comparative case-control study between successful cases of primary PTCA with and without stenting in seven cardiovascular centres involved in the NORTH (network of revascularisation therapy in Hokkaido) investigations.

\section{Methods}

PATIENT POPULATION

Forty five consecutive patients with acute myocardial infarction treated by successful and uncomplicated primary stenting (Stent group) and who did not have restenosis were prospectively enrolled between January 1996 and December 1998. 
Table 1 Clinical and angiographic characteristics of the study groups

\begin{tabular}{|c|c|c|c|}
\hline & Stent $(n=45)$ & $P O B A(n=45)$ & $p$ Value \\
\hline Age (years) & $62.1(11.0)$ & $61.4(10.9)$ & 0.762 \\
\hline Sex (male) & $35(78 \%)$ & $32(71 \%)$ & 0.629 \\
\hline \multicolumn{4}{|l|}{ Coronary risk factors } \\
\hline Hypertension & $20(44 \%)$ & $24(53 \%)$ & 0.527 \\
\hline Hyperlipidaemia & $20(44 \%)$ & $11(24 \%)$ & 0.076 \\
\hline Diabetes mellitus & $12(27 \%)$ & $12(27 \%)$ & 0.812 \\
\hline Smoking & $27(60 \%)$ & $29(63 \%)$ & 0.828 \\
\hline Previous MI (LAD/RCA/LCx) & $4(2 / 1 / 1)$ & $1(0 / 0 / 1)$ & 0.357 \\
\hline Preinfarction angina & $23(51 \%)$ & $29(63 \%)$ & 0.286 \\
\hline Killip class $\geqslant I I$ & $6(11 \%)$ & $3(7 \%)$ & 0.482 \\
\hline \multicolumn{4}{|l|}{ Coronary angiography } \\
\hline Infarct related artery $(\mathrm{LAD} / \mathrm{RCA} / \mathrm{LCx})$ & $(20 / 20 / 5)$ & $(20 / 20 / 5)$ & 1 \\
\hline Lesion numbers (SVD/DVD/TVD) & $(34 / 10 / 1)$ & $(35 / 9 / 1)$ & 0.967 \\
\hline Collateral grade $(\geqslant 2 /<2)$ & $15 / 30$ & $15 / 30$ & 0.823 \\
\hline \multicolumn{4}{|l|}{ Angioplasty } \\
\hline Time to reperfusion (h) & $8.3(9.4)$ & $5.4(4.5)$ & 0.065 \\
\hline \multicolumn{4}{|l|}{ Postprocedural QCA } \\
\hline Reference (mm) & $3.23(0.32)$ & $3.08(0.36)$ & 0.04 \\
\hline $\operatorname{MLD}(\mathrm{mm})$ & $2.80(0.60)$ & $2.34(0.29)$ & 0.0001 \\
\hline$\%$ Diameter stenosis & $13.6(7.3)$ & $24.0(4.5)$ & 0.0001 \\
\hline \multicolumn{4}{|l|}{ Follow up QCA } \\
\hline Interval (d) & $28.1(10.0)$ & $28.0(6.3)$ & 0.955 \\
\hline Reference (mm) & $3.28(0.31)$ & $3.12(0.38)$ & 0.031 \\
\hline $\operatorname{MLD}(\mathrm{mm})$ & $2.74(0.37)$ & $2.36(0.39)$ & 0.0001 \\
\hline$\%$ Diameter stenosis & $16.6(7.6)$ & $24.8(6.1)$ & 0.0001 \\
\hline \multicolumn{4}{|l|}{ Drug treatment } \\
\hline ACE inhibitor & $18(40 \%)$ & $24(53 \%)$ & 0.291 \\
\hline Calcium antagonist & $14(31 \%)$ & $12(27 \%)$ & 0.816 \\
\hline Nitrates & $43(96 \%)$ & $38(84 \%)$ & 0.16 \\
\hline$\beta$ Blockade & $9(20 \%)$ & $8(18 \%)$ & 1 \\
\hline
\end{tabular}

Values are mean (SD) or $\mathrm{n}(\%)$.

ACE, angiotensin converting enzyme; DVD, double vessel disease; LAD, left anterior descending coronary artery; LCx, left circumflex coronary artery; MI, myocardial infarction; MLD, minimum lumen diameter; QCA, quantitative coronary angiography; RCA, right coronary artery; SVD, single vessel disease; TVD, triple vessel disease.

The inclusion criteria were as follows:

- an unequivocal diagnosis of acute myocardial infarction on the basis of chest pain persisting more than 30 minutes and less than 24 hours, ST segment elevation of at least $0.1 \mathrm{mV}$ in two or more ECG leads, and an elevation of creatine kinase;

- age under 80 years;

- successful primary PTCA, defined as a residual stenosis $<50 \%$ with TIMI (thrombolysis in myocardial infarction) grade 3 flow. ${ }^{21}$

The exclusion criteria were as follows:

- presence of mechanical complications, such as ventricular septal perforation, cardiac rupture, or papillary muscle rupture;

- postinfarction cardiogenic shock or uncontrollable congestive heart failure;

- angiographic restenosis of the infarcted vessel, defined as $\geqslant 50 \%$ diameter stenosis, or cardiac event including abrupt closure during the follow up period;

- presence of cardiogenic shock or the need for urgent intra-aortic balloon pumping before primary coronary angioplasty,

- previous coronary artery bypass grafting, or recent (within six months) coronary intervention;

- surgical and repeat non-surgical revascularisation of the infarct related artery;

- left main coronary artery stenosis $\geqslant 50 \%$.

The controls were 45 patients with acute myocardial infarction treated by successful (optimal) primary PTCA without stenting (plain old balloon angioplasty (POBA) group); they were also prospectively enrolled from each institute and were paired with the patients in the Stent group. The controls were closely matched to the Stent group in terms of age, month of revascularisation (between January 1996 and December 1998), angiographic findings (vessel numbers involved, collateral grade before revascularisation, and infarct related coronary artery), and inclusion/exclusion criteria. If Stent group patients fulfilled the exclusion criteria mentioned above owing to restenosis and cardiovascular complications, both patients were excluded from the study.

All patients in the Stent and POBA groups had an infarct related artery with a reference diameter of $>2.5 \mathrm{~mm}$. While all the target lesions were carefully examined retrospectively by HS and KT for their suitability for stent deployment, using previously validated criteria, ${ }^{17}$ selection for stenting was nonrandomised. Bailout stent cases following suboptimal results or massive dissection after primary PTCA were not included in the Stent group. A coil stent was used in eight cases (Wiktor in six, GR-II in two), and a rigid stent in 37 cases (Palmatz-Schatz in 15, Multi-link in 12 , GFX in 10). The diameter of the stent was at least $3.0 \mathrm{~mm}$ in all cases.

During the acute intervention, heparin (150 units $/ \mathrm{kg}$ ) was given intravenously, and this was continued in a maintenance dose of $150 \mathrm{units} / \mathrm{kg} /$ day for three days after angioplasty; subsequently oral aspirin ( $81 \mathrm{mg} /$ day) was prescribed in all cases. In subjects with stenting, the antiplatelet agent ticlopidine ( $200 \mathrm{mg} /$ day) was given throughout the study to prevent abrupt thrombotic closure. Warfarin administration was indicated in 10 subjects in the Stent group and 10 in the POBA group.

CLINICAL CHARACTERISTICS

The clinical characteristics of the subjects are summarised in table 1 . These included coronary risk factors (hypertension, hyperlipidaemia, diabetes mellitus, smoking), preinfarction angina (defined as chest pain episodes limited to the 48 hours before infarction), Killip classification on admission, time from symptom onset to revascularisation, peak creatine kinase value, and drug treatment given after admission (angiotensin converting enzyme (ACE) inhibitors, calcium antagonists, nitrates, and $\beta$ blockers).

QUANTITATIVE CORONARY ANGIOGRAPHY

Quantitative coronary angiography of the infarct related artery was performed with a contrast filled catheter as a reference. The diameters of the normal segments proximal and distal to the treated area were averaged to determine the reference diameter. The minimum lumen diameter and the percentage diameter stenosis were calculated by single plane, worst view angulation. Collateral flow was graded from the initial angiography according to the scale described by Rentrop and colleagues, ${ }^{22}$ as follows: grade 3, complete filling of the epicardial segment; grade 2, partial filling of the epicardial segment; grade 1 , filling of side branches without visualisation of the epicardial segment; grade 0 , no collaterals. 
Table 2 Left ventricular function after myocardial infarction

\begin{tabular}{|c|c|c|c|c|c|c|}
\hline & \multicolumn{2}{|l|}{ All $(n=45)$} & \multicolumn{2}{|l|}{$L A D(n=20)$} & \multicolumn{2}{|c|}{ Non-LAD $(n=25)$} \\
\hline & Stent & $P O B A$ & Stent & POBA & Stent & $P O B A$ \\
\hline Time after reperfusion (days) & $28.1(10.0)$ & $28.0(6.3)$ & $29.3(11.7)$ & $29.2(5.6)$ & $27.2(8.6)$ & $27.1(6.7)$ \\
\hline \multicolumn{7}{|l|}{ Volumetry analysis } \\
\hline Global ejection fraction (\%) & $61.4(11.3)$ & $56.8(11.3)$ & $63.3(10.2)$ & $51.7(11.7)^{\star}$ & $60.0(12.1)$ & $60.9(9.3)$ \\
\hline Regional function (SD/chord) & $-0.34(1.59)$ & $-1.07(1.58)^{\star}$ & $0.28(1.49)$ & $-1.30(1.78)^{\star}$ & $-0.83(1.52)$ & $-0.88(1.40)$ \\
\hline \multicolumn{7}{|l|}{ Infarct size analysis } \\
\hline Risk area (chords) & $43.5(12.2)$ & $43.6(14.3)$ & $54.5(5.8)$ & $57.4(6.3)$ & $34.6(7.9)$ & $32.6(7.8)$ \\
\hline Hypokinesis area (chords) & $17.6(16.8)$ & $24.8(21.6)$ & $15.1(20.0)$ & $34.4(24.3)^{\star}$ & $20.8(15.1)$ & $18.4(17.3)$ \\
\hline Hypokinesis area/risk area (\%) & $40.3(34.8)$ & $52.7(39.8)$ & $25.2(31.9)$ & $58.8(40.1)^{\star}$ & $51.9(33.0)$ & $47.8(39.7)$ \\
\hline Peak CK (IU/1) & $2645(1623)$ & $2489(1752)$ & $1935(1368)$ & $2950(1853)$ & $2888(1711)$ & $2119(1609)$ \\
\hline Scintigraphic score & $9.4(6.4)$ & $9.8(7.0)$ & $10.0(7.0)$ & $11.9(8.7)$ & $8.2(3.8)$ & $8.4(5.2)$ \\
\hline
\end{tabular}

Values are mean (SD).

* Significantly different from Stent group.

$\mathrm{CK}$, creatine kinase; LAD, left anterior descending coronary artery lesion.

QUANTITATIVE ASSESSMENT OF REGIONAL WALL MOTION

Regional wall motion of the left ventricle was assessed by the centreline method, ${ }^{23}$ using contrast left ventriculography in the $30^{\circ}$ right anterior oblique projection, during the subacute phase (mean (SD) time after onset of infarction, 28 (8) days), at the same time as follow up coronary angiography. The area of myocardium at risk (risk area) was angiographically defined as the area depicted on the $30^{\circ}$ right anterior oblique projection that was supplied by the infarct related coronary artery. ${ }^{24}$ The proximal limit of the risk area was taken from the "culprit" lesion-defined as either the lesion associated with total occlusion or thrombus, or the most proximal severe stenosis. The distal limit of the risk area was defined as the termination of the infarct related artery, as viewed in the right anterior oblique projection. The proximal and distal limits were marked on the diastolic contour, and the chords thus encompassed were described as the risk area. In subjects with infarction caused by a left circumflex coronary artery lesion, only those with a dominant left circumflex artery were included.

Reference values were derived from 50 angiographically normal control subjects investigated in our laboratory, who were considered to have normal left ventricular function. Regional wall motion abnormality, or hypokinesis area, was defined as chord numbers with depression of regional shortening to $<-1 \mathrm{SD}$ of the control values. Left ventricular ejection fraction was calculated by the area-length method. The mean (SD) chord values of the risk area were quantified as a regional function of the risk area.

\section{SINGLE PHOTON EMISSION COMPUTED}

TOMOGRAPHY IMAGING

Myocardial perfusion single photon emission computed tomography (SPECT) with thallium-201 (74-111 MBq) or technetium$99 \mathrm{~m}$-tetrofosmin (600-740 MBq) was performed in the subacute phase (20.9 (10.4) days) in $40(89 \%)$ of the 45 patients in the Stent group and in $39(87 \%)$ of the 45 patients in the POBA group. Myocardial uptakes on perfusion SPECT were assessed visually by three nuclear cardiologists using a four point scoring system as follows: 0 , normal; 1 , mildly reduced; 2, notably reduced; 3, perfusion defect present in 19 left ventricular segments on basal, middle, apical short axis, and long axis slices. A defect score was calculated as the summation of all the scores.

\section{STATISTICAL ANALYSIS}

All data are expressed as mean (SD). Differences between mean values in the two groups were compared using an unpaired $t$ test. Incidences between the two groups were compared by the $\chi^{2}$ test. Correlations between two variables were determined using linear regression analysis. Differences in regression lines between the risk area and the hypokinesis area in the two groups were tested for by analysis of covariance for both intercepts and gradients.

To determine independent explanatory factors correlated with infarct size reduction, we used an SPSS Advanced Statistics 6.1 package for Macintosh (SPSS Japan). Multiple logistic regression analysis was carried out after identification of significant factors on single logistic regression analysis, using (a) all subjects and (b) those with left anterior descending coronary artery lesions. Odds ratios (OR) and 95\% confidence intervals (CI) were calculated. We included preinfarction angina (presence or absence), method of primary PTCA (stenting or POBA), revascularisation time ( $\leqslant 3$ hours or $>3$ hours), collateral grade ( $\geqslant$ grade 2 or $<$ grade 2$)$, per cent diameter stenosis $(\leqslant 20 \%$ or $>20 \%$ ), and ACE inhibitor treatment (taken after infarction or not) as factors in the multiple logistic regression analysis.

\section{Results}

CLINICAL AND ANGIOGRAPHIC CHARACTERISTICS Table 1 shows the clinical and angiographic characteristics of the two groups. There were no significant differences between them in terms of age, sex, coronary risk factors, preinfarction angina, Killip classification, or drugs taken after myocardial infarction. The distribution of the infarct related arteries was the same in each group (left anterior descending, 20; left circumflex, 5; right coronary, 20). There was no significant difference in the number of subjects with multivessel disease between the two groups (11 in the Stent group, 10 in the POBA group). In subjects with left anterior descending coronary artery lesions, proximal lesions before the first septal branch were seen in 11 $(55 \%)$ of the Stent group and in seven $(35 \%)$ of 
A

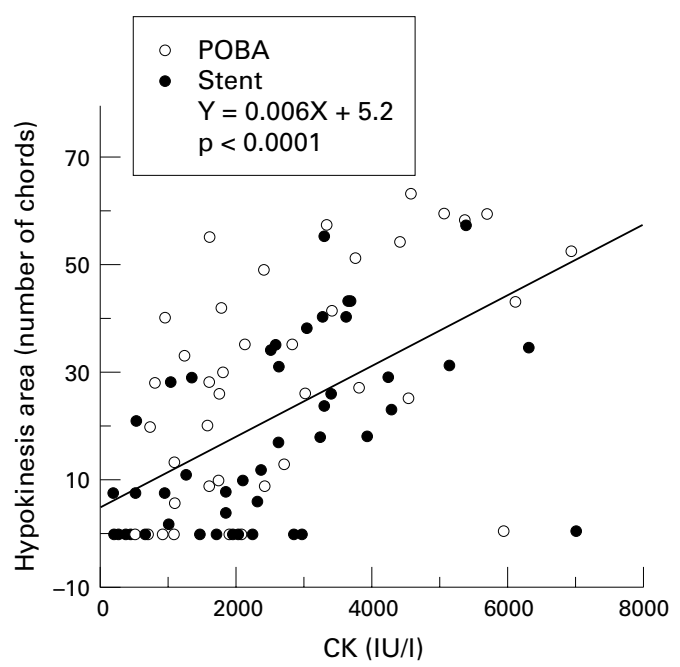

B

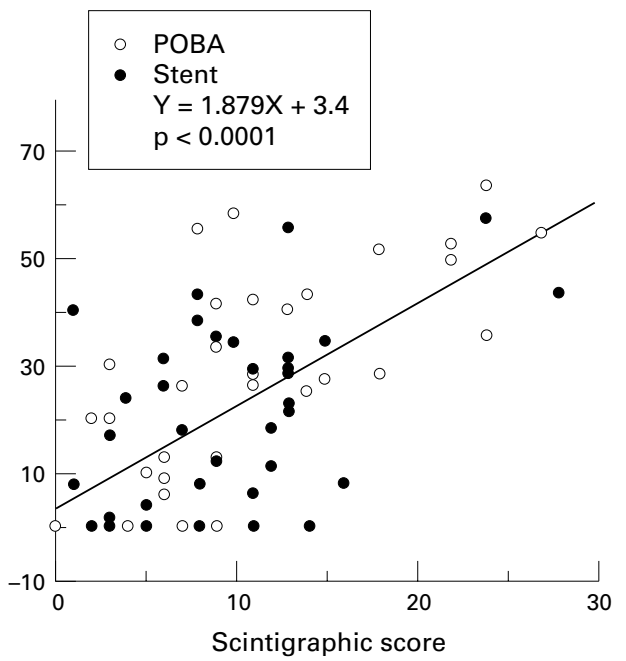

Figure 1 Hypokinesis area on quantitative left ventriculography positively correlated with peak creatine kinase values (peak CK, left panel) and scintigraphic scores (right panel).

the POBA group. There was no significant difference between the two groups in the number of subjects who had previous myocardial infarction (four in the Stent group, one in the POBA group). Collateral grades between the two groups were the same. The Stent group had a longer time to reperfusion from symptom onset than the POBA group (mean (SD)), at $8.3(9.4) \cup 5.4(4.5)$ hours $(\mathrm{p}=0.065)$. The incidence of very early revascularisation $(<3$ hours after onset) was $7 \%$ in the Stent group and $36 \%$ in the POBA group.

The Stent group had a significantly larger reference diameter and minimum lumen diameter and a smaller per cent diameter stenosis than the POBA group, as determined by the postprocedural and follow up quantitative coronary angiography. In the Stent group, drug induced rashes, bleeding complications requiring blood transfusion, dopamine use, and

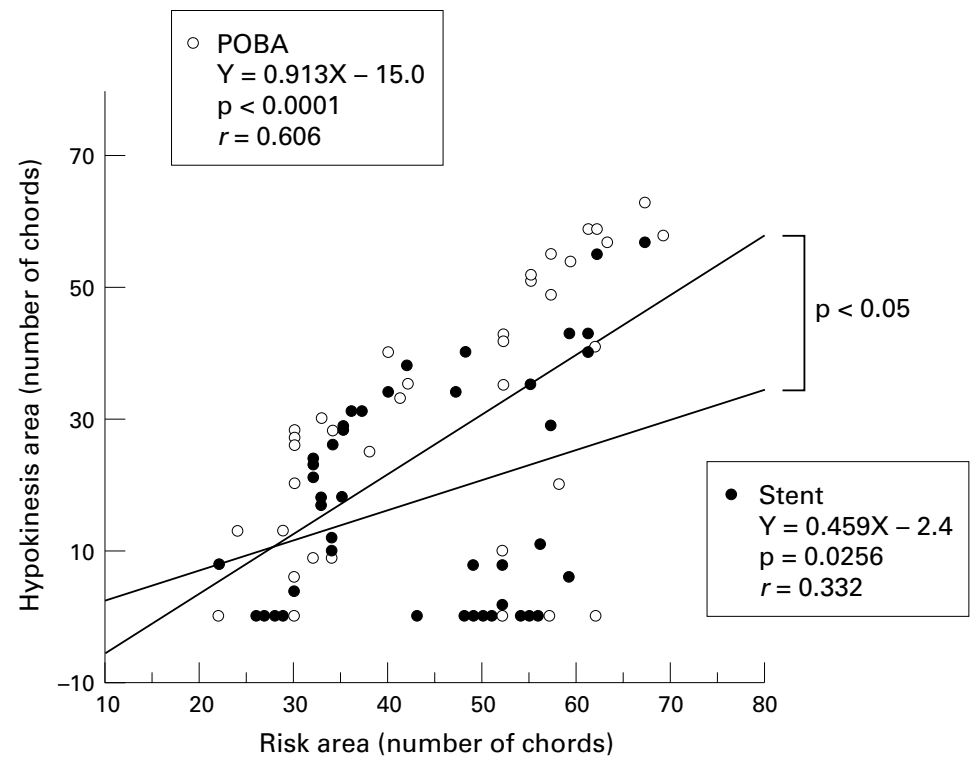

Figure 2 Correlation between risk area and hypokinesis area in patients with primary angioplasty with stenting (Stent, filled circles) and without stenting (POBA, empty circles). In both the Stent group and the POBA group, there was a significant positive correlation between the risk area and the hypokinesis area; however, the regression line in the Stent group showed a downward shift, indicating a myocardial protective effect of coronary stenting. symptomatic heart failure at discharge (exceeding New York Heart Association functional class II) occurred in $4.4 \%, 4.4 \%, 24.4 \%$, and $2.2 \%$, respectively; the corresponding values in the POBA group were $7.6 \%, 4.2 \%$, $26.7 \%$, and $2.0 \%$.

LEFT VENTRICULAR FUNCTION AFTER

MYOCARDIAL INFARCTION

Table 2 shows the results of the analysis of left ventricular function in the subacute phase. In all subjects, the averaged $\mathrm{SD}$ /chord of the risk area in the Stent group was smaller than in the POBA group, but there were no significant differences in left ventricular ejection fraction, risk area, hypokinesis area, hypokinesis area to risk area ratio, peak creatine kinase, or scintigraphic score between the two groups. However, in subjects with left anterior descending coronary artery lesions, the Stent group had a lower hypokinesis area and hypokinesis area to risk area ratio, and a higher ejection fraction and average $\mathrm{SD}$ /chord values of the risk area than the POBA group. In subjects with lesions in the other coronary arteries, there were no significant differences in left ventricular ejection fraction, average $\mathrm{SD}$ /chord values of the risk area, risk area, hypokinesis area, hypokinesis area to risk area ratio, peak creatine kinase, and scintigraphic score between the two groups.

There were significant correlations between hypokinesis area and peak creatine kinase and scintigraphic defect score (fig 1). Figure 2 shows the correlations between risk area and hypokinesis area in the Stent and POBA groups. Risk area was correlated with hypokinesis area in both groups, and the regression line between risk area and hypokinesis area in the Stent group was shifted downward compared with the POBA group. These findings indicate that the ratio of hypokinesis area to risk area in the Stent group was smaller than in the POBA group. On the other hand, there were no significant correlations between the hypokinesis area to risk area ratio, minimum lumen diameter, or per cent diameter stenosis. 
Table 3 Clinical and angiographic characteristics classified by hypokinesis area to risk area (H:R) ratio

\begin{tabular}{|c|c|c|c|c|c|c|}
\hline & \multicolumn{3}{|l|}{ All subjects } & \multicolumn{3}{|c|}{ LAD involvement } \\
\hline & $\begin{array}{l}H: R<50 \% \\
(n=41)\end{array}$ & $\begin{array}{l}H: R \geqslant 50 \% \\
(n=49)\end{array}$ & p Value & $\begin{array}{l}H: R<50 \% \\
(n=21)\end{array}$ & $\begin{array}{l}H: R \geqslant 50 \% \\
(n=19)\end{array}$ & $p$ Value \\
\hline Age (years) & $63.5(9.8)$ & $60.3(11.7)$ & 0.17 & $63.4(8.1)$ & $59.0(10.0)$ & 0.13 \\
\hline \multicolumn{7}{|l|}{ Coronary risk (\%) } \\
\hline Hypertension & $21(51 \%)$ & $23(47 \%)$ & 0.85 & $9(43 \%)$ & $12(63 \%)$ & 0.33 \\
\hline Hyperlipidaemia & $16(39 \%)$ & $15(31 \%)$ & 0.54 & $10(48 \%)$ & $7(37 \%)$ & 0.71 \\
\hline Diabetes mellitus & $13(32 \%)$ & $11(22 \%)$ & 0.45 & $5(24 \%)$ & $6(32 \%)$ & 0.85 \\
\hline Smoking & $23(56 \%)$ & $33(67 \%)$ & 0.38 & $12(57 \%)$ & $15(79 \%)$ & 0.26 \\
\hline Preinfarction angina & $30(73 \%)$ & $22(45 \%)$ & 0.01 & $17(81 \%)$ & $9(47 \%)$ & 0.06 \\
\hline \multicolumn{7}{|l|}{ Coronary angiography } \\
\hline Infarct related artery (LAD/RCA/LCx) & $(21 / 17 / 3)$ & $(19 / 23 / 7)$ & 0.39 & - & - & - \\
\hline Collateral grade $\geqslant 2$ & $14(34)$ & $16(33)$ & 0.94 & $6(29)$ & $8(42)$ & 0.57 \\
\hline $\mathrm{DS} \geqslant 20 \%(\%)$ & $28(68)$ & $24(49)$ & 0.10 & $15(71)$ & $9(47)$ & 0.22 \\
\hline \multicolumn{7}{|l|}{ Angioplasty } \\
\hline Stent $(\%)$ & $23(56)$ & $22(45)$ & 0.40 & $14(67)$ & $6(32)$ & 0.06 \\
\hline Reperfusion $\geqslant 3$ hours (\%) & $6(15)$ & $13(27)$ & 0.26 & $5(25)$ & $5(26)$ & 0.86 \\
\hline ACE inhibitor & $19(46 \%)$ & $23(47 \%)$ & 0.88 & $15(71 \%)$ & $13(68 \%)$ & 0.89 \\
\hline
\end{tabular}

Values are mean (SD) or $\mathrm{n}(\%)$.

ACE, angiotensin converting enzyme; DS, diameter stenosis; LAD, left anterior descending coronary artery; LCx, left circumflex coronary artery; RCA, right coronary artery.

MULTIPLE LOGISTIC ANALYSIS OF LEFT

VENTRICULAR FUNCTION

The hypokinesis area to risk area ratio is an index of protection from myocardial injury. We analysed separately those subjects with hypokinesis area/risk area $<50 \%$ and $\geqslant 50 \%$. The clinical and angiographic characteristics of these two groups are shown in table 3 . Compared with a value of $\geqslant 50 \%$, subjects with a value $<50 \%$ had a higher incidence of preinfarction angina $(73 \% v 45 \%, \mathrm{p}=0.013)$ in all subjects, and both a higher incidence of preinfarction angina ( $81 \% v 47 \%, \mathrm{p}=0.059)$ and of stenting $(67 \% v 32 \%, \mathrm{p}=0.057)$ in subjects with left anterior descending coronary artery lesions.

Single logistic regression analysis showed that hypokinesis area/risk area $<50 \%$ was significantly correlated with preinfarction angina in all subjects, and with preinfarction angina and stenting in the subjects with left anterior descending coronary artery lesions, but not with time to reperfusion ( $\leqslant 3$ hours, $\mathrm{p}=0.2379$ ), collateral grade (grade $\geqslant 2$, $\mathrm{p}=0.8369)$, per cent diameter stenosis ( $\leqslant 20 \%, p=0.0659)$, or ACE inhibitor treatment ( $p=0.4075)$. Multiple logistic regression analysis showed that preinfarction angina $(\mathrm{p}=0.0189, \mathrm{OR}=3.260)$ in all subjects, and preinfarction angina $(\mathrm{p}=0.0399, \mathrm{OR}=4.896)$ and stenting $(\mathrm{p}=0.0391, \mathrm{OR}=4.486)$ in the left anterior descending artery subjects were the significant explanatory factors (table 4 ).

Table 4 Multiple logistic regression analysis on preserved ventricular function after successful revascularisation

\begin{tabular}{lll}
\hline Variable & $p$ Value & Odds ratio (95\% CI) \\
\hline $\begin{array}{l}\text { All cases } \\
\text { Preinfarction angina }\end{array}$ & 0.0189 & 3.26 (1.22 to 8.75) \\
$\quad \begin{array}{l}\text { Positive } \\
\quad \text { Negative }\end{array}$ & 0.0296 & 1 \\
Constant & & \\
LAD & & \\
$\quad \begin{array}{l}\text { Method of } \\
\text { revascularisation }\end{array}$ & 0.0391 & $4.49(1.08$ to 18.67$)$ \\
$\quad \begin{array}{l}\text { Stent } \\
\quad \text { POBA }\end{array}$ & & 1 \\
$\quad \begin{array}{l}\text { Preinfarction angina } \\
\quad \text { Positive }\end{array}$ & 0.0399 & $4.90(1.08$ to 22.23) \\
$\quad$ Negative & 0.0268 & 1 \\
$\quad$ Constant & & \\
\hline
\end{tabular}

\section{Discussion}

Our study suggests that primary stenting in anterior acute myocardial infarction is more effective in preventing myocardial injury and restoring left ventricular function than POBA.

PRIMARY STENTING OF THE INFARCT RELATED ARTERY IN ACUTE MYOCARDIAL INFARCTION As in elective PTCA, ${ }^{13}$ bailout stenting of the infarcted vessel has been reported to be feasible and safe, with low rates of restenosis and major adverse cardiac events. ${ }^{14-16}$ Prospective randomised trials of primary stenting are now in progress, and the FRESCO $^{17}$ (Florence randomised elective stenting in acute coronary occlusions) and Zwolle ${ }^{19}$ trials have now documented lower restenosis rates when this is done. However, there is no clear clinical evidence of cardioprotective effects with primary stenting. For example, in the FRESCO and Zwolle trials, no data on regional wall motion abnormalities or left ventricular functional recovery in the subacute or chronic phases were shown. Because the present study was not designed to investigate angiographic restenosis or cardiovascular accidents, we cannot comment on whether primary stenting should be performed in all cases of primary PTCA. Our study, however, suggests that primary stenting is effective at preserving left ventricular function in subjects with infarcts in the left anterior descending coronary artery territory.

Coronary blood flow studies in elective PTCA and stenting have shown that stenting is superior to POBA at improving coronary vasodilator reserve. ${ }^{20}$ In another study of acute myocardial infarction it was found that stenting was superior to POBA in improving coronary blood flow, as measured by the TIMI frame count method. ${ }^{25}$ In acute myocardial infarction, the coronary vasodilator reserve may influence left ventricular expansion (aneurysm formation) and wall motion recovery (myocardial remodelling). Although we did not assess coronary vasodilator reserve in the present study, we suggest that primary stenting may be superior to POBA at improving the reserve in patients with anterior acute myocardial 
infarction, thereby resulting in an augmented improvement of regional wall motion. Though there were intergroup differences in lumen diameter and per cent diameter stenosis between the Stent group and the POBA group, hypokinesis area was not significantly correlated with minimum lumen diameter or per cent diameter stenosis. Therefore, significant differences in the hypokinesis area to risk area ratio or in the ejection fraction between the two groups were not influenced by minimum lumen diameter or per cent diameter stenosis.

INFARCT LOCATION AND PREINFARCTION ANGINA Thrombolytic treatment produces a reduction in infarct size and preserves the ejection fraction in both anterior and non-anterior myocardial infarction. ${ }^{26}{ }^{27}$ However, no survival benefit has been shown for primary or rescue PTCA in inferior myocardial infarction except in cases of cardiogenic shock or right ventricular infarction. ${ }^{68}$ In the present study we showed that primary stenting was no more effective than POBA in restoring left ventricular function in patients who had infarcts outside the left anterior descending artery territory. There could be several reasons for this. First, the amount of myocardium at risk is greatest with left anterior descending lesions, so primary stenting may be expected to be more effective at that site. Second, regional wall motion was assessed only by a single projection in this study, so the risk areas obtained for the circumflex and right coronary arteries were small.

Brief ischaemic episodes preceding prolonged coronary occlusion (ischaemic preconditioning) cause a reduction in infarct size. A previous study showed that preinfarction angina also reduced infarct size in the human heart. ${ }^{29}$ In a scintigraphic study from our department using thallium-201 and iodine-123 BMIPP tomography, it was shown that preinfarction angina preserved myocardial viability at the expense of fatty acid metabolism, resulting in augmentation of perfusion-metabolism mismatch and functional improvement in patients undergoing successful reperfusion. ${ }^{30}$ Unfortunately, in that series the perfusion tracer studies were done only in the subacute period and the number of subjects was small, so we could only reveal the area of irreversible myocardial damage. Serial examinations focusing on correlations between perfusion-metabolism mismatch and perfusion recovery may show more clearly the beneficial effect of direct stenting. In the present study, we found by multiple logistic regression analysis that preinfarction angina was a significant explanatory factor in the preservation of wall motion. As preinfarction angina and stenting were independent explanatory factors for improved left ventricular function in subjects with left anterior descending coronary artery lesions, primary stenting in patients with preinfarction angina could augment the wall motion preserving effects of angina.
STUDY LIMITATIONS

Restenosis, complications and adverse clinical events, and symptomatic heart failure are the important determinants of outcome in primary stenting for acute myocardial infarction. We could show rates for only a few of the complications (drug eruptions, bleeding complications requiring blood transfusion, dopamine use, symptomatic heart failure on discharge). However, the aim of our study was only to test whether successful primary stenting could be more beneficial in restoring left ventricular function than optimal POBA. Subjects with suboptimal results, abrupt closure, restenosis, reinfarction, repeated and added surgical or non-surgical revascularisation, and cardiac death were excluded. Thus we are unable to comment on some of the important information that is required before decisions can be made about methods of revascularisation in acute myocardial infarction. Furthermore, our study did not clarify whether primary stenting for acute myocardial infarction can reduce postinfarction heart failure in the chronic phase, or improve long term mortality. Therapeutic cost-effectiveness was also not investigated. A final limitation is that the Stent group subjects (cases) and POBA group subjects (controls) were enrolled prospectively, but the study was not designed as a prospective randomised trial.

\section{CONCLUSION}

Primary stenting in anterior acute myocardial infarction may be an effective therapeutic option for preventing myocardial injury and preserving regional wall motion and left ventricular function.

We would like to express special thanks to all the members of NORTH (network of revascularization therapy in Hokkaido) investigators for their encouragement and advice during this project. The NORTH-981 investigators were as follows:
Sapporo Medical University Hospital, Sapporo: H Sasao, K Tsuchihashi, K Shimamoto; Hakodate Goryoukaku Hospital, Hakodate: K Nagao, A Endoh; Muroran City General Hospital, Hakodate: K Nagao, A Endoh; Muroran City General Hospital,
Muroran: T Adachi, M Fukuoka; Muroran Shinnittetsu HospiMuroran: T Adachi, M Fukuoka; Muroran Shinnittetsu Hospital, Muroran: T Matsuki; Sapporo Junkanki Clinic, Sapporo: H Kobayashi, M Tsuzuki; Teine Keijinkai Hospital, Sapporo: N A Hashimoto, N Yoshioka.

1 O'Keefe JH, Rutherford BD, McConahay DR, et al. Early and late results of coronary angioplasty without antecedent thrombolytic therapy for acute myocardial infarction. Am $\mathcal{F}$ Cardiol 1989;64:1221-30.

2 Grines CL, Browne KF, Marco J, et al. A comparison of immediate angioplasty with thrombolytic therapy for acute myocardial infarction. $N$ Engl $\mathcal{F}$ Med 1993;328:673-9.

3 (GUSTO IIb) angioplasty substudy investigators. The global use of strategies to open occluded coronary arteries in acute coronary syndromes. A clinical trial comparing primary coronary angioplasty with tissue plasminogen actiprimary coronary angioplasty with tissue plasminogen activator for acute myc

4 Ellis SG, O'Neill Ww, Bates ER, et al. Implications for patient triage from survival and left ventricular functional recovery analyses in 500 patients treated with coronary angioplasty for acute myocardial infarction. $\mathcal{F} \mathrm{Am}$ Coll Cardiol 1989;13:1251-9.

5 Hashimoto A, Nakata T, Tsuchihashi K, et al. Postischemic functional recovery and BMIPP uptake after primary percutaneous transluminal coronary angioplasty in acute myocardial infarction. Am f Cardiol 1996;77:25-30.

6 Stone GW, Grines CL, Browne KF, et al. Influence of acute myocardial infarction location on in-hospital and late outrocarditer come after primary percutaneous transluminal coronary angioplasty versus tissue pla

7 Zijlstra F, de Boer MJ, Hoorntje JCA, et al. A comparison of immediate coronary angioplasty with intravenous streptokinase in acute myocardial infarction. $N$ Engl $f \mathrm{Med}$ 1993;328:680-4. 
8 Rothbaum DA, Linnemeier TJ, Landin RJ, et al. Emergency percutaneous transluminal coronary angioplasty in acute myocardial infarction: a 3 year experience. $f \mathrm{Am} \mathrm{Coll}$ Cardiol 1987;10:264-72.

9 Brodie BR, Grines CL, Ivanhoe R, et al. Six-month clinical and angiographic follow-up after direct angioplasty for acute myocardial infarction. Final results from the primary angioplasty registry. Circulation 1994;25:156-62.

10 Nakagawa Y, Iwasaki Y, Kimura T, et al. Serial angiographic follow-up after successful direct angioplasty for acute myofollow-up after successful direct angioplasty for

11 Ito $\mathrm{H}$, Tomooka T, Sakai N, et al. Lack of myocardial perfusion immediately after successful thrombolysis. A predictor of poor recovery of left ventricular function in anterior myocardial infarction. Circulation 1992;85:1699705.

12 Ishihara $\mathrm{M}$, Sato $\mathrm{H}$, Tateishi $\mathrm{H}$, et al. Impaired coronary flow reserve immediately after coronary angioplasty in patients with acute myocardial infarction. Br Heart $\mathcal{f} 1993$; 69:288-92.

13 Fischman DL, Leon MB, Baim DS, et al. A randomized comparison of coronary-stent placement and balloon angioplasty in the treatment of coronary artery disease. $N$ Engl f Med 1994;331:496-501.

14 Rodriguez AE, Fernandez M, Santaera O, et al. Coronary stenting in patients undergoing percutaneous transluminal coronary angioplasty during acute myocardial infarction. Am 7 Cardiol 1996;77:685-9.

15 Neumann FJ, Walter H, Richardt G, et al. Coronary Palmaz-Schatz stent implantation in acute myocardial infarction. Heart 1996;75:121-6.

16 Garcia-Cantu E, Spaulding C, Corcos T, et al. Stent implantation in acute myocardial infarction. $\mathrm{Am} \mathcal{F}$ Cardio 1996;77:451-4.

17 Antoniucci D, Santoro GM, Bolognese L, et al. A clinical trial comparing primary stenting of the infarct-related artery with optimal primary angioplasty for acute myocardial infarction. Results from the Florence randomized elective stenting in acute coronary occlusions (FRESCO) Trial. $7 \mathrm{Am}$ Coll Cardiol 1998;31:1234-9.

18 Stone GW, Brodie BR, Griffin J, et al. Prospective, multicenter study of the safety and feasibility of primary stenting in acute myocardial infarction: in-hospital and 30 -day results of the PAMI stent pilot trial. $\mathcal{f} \mathrm{Am}$ Coll Cardiol 1998;31:23-30.
19 Suryapranata H, van't Hof AWJ, Hoorntje JCA, et al. Randomized comparison of coronary stenting with balloon omized comparison of coronary stenting with balloon angioplasty in selected patients with

20 Kern MJ, Dupouy P, Drury JH, et al. Role of coronary artery lumen enlargement in improving coronary blood flow after balloon angioplasty and stenting: a combined intravascular ultrasound Doppler flow and imaging study. $\mathcal{F}$ Am Coll Cardiol 1997;29:1520-7.

21 The TIMI study group. The thrombolysis in myocardial infarction (TIMI) trial: phase I findings. $N$ Engl $\mathcal{F} \mathrm{Med}$ 1985;312:932-6.

22 Rentrop KP, Cohen $\mathrm{M}$, Blanke $\mathrm{H}$, et al. Changes in collateral filling immediately after controlled coronary artery occlusion by an angioplasty balloon in human subjects. F Am Coll Cardiol 1985;5:587-92.

23 Sheehan FH, Bolson EL, Dodge HT, et al. Advantages and applications of the centerline method for characterizing regional ventricular function. Circulation 1986;74:293-305.

24 Cross DB, Ashton NG, Norris RM, et al. Comparison of the effects of streptokinase and tissue plasminogen activator on
regional wall motion after first myocardial infarction: analysis by the centerline method with correction for area at risk. F Am Coll Cardiol 1991;17:1039-46.

25 Edep ME, Guarneri EM, Teirstein PS, et al. Differences in TIMI frame count following successful reperfusion with stenting or percutaneous transluminal coronary angioplasty for acute myocardial infarction. $\mathrm{Am} \mathcal{f}$ Cardiol 1999;83:1326-9.

26 Ritchie JL, Davis KB, Williams DL, et al. Global and regional left ventricular function and tomographic radionuclide perfusion: the Western Washington intracoronary streptokinase in myocardial infarction trial. Circulation 1984;70:867-75.

27 O'Rourke M, Baron D, Keogh A, et al. Limitation of myocardial infarction by early infusion of recombinant tissue-type plasminogen activator. Circulation 1988;77: tissue-type

28 Bates ER. Revisiting reperfusion therapy in inferior myocardial infarction. 7 Am Coll Cardiol 1997;30:334-42.

29 Ottani F, Galvani M, Ferrini D, et al. Prodromal angina limits infarct size. A role for ischemic preconditioning. Circulaits infarct size. A role

30 Nakata T, Hashimoto A, Kobayashi H, et al. Outcome significance of thallium-201 and iodine-123-BMIPP perfusion-metabolism mismatch in preinfarction angina. $\mathcal{F}$ Nucl Med 1998;39:1492-9.

\section{Electronic pages}

\section{eHEART: www.heartjnl.com}

The following electronic only articles are published in conjunction with this issue of Heart.

\section{Novel expression of VCAM-1 on the mitral valve in a patient with primary antiphospholipid antibody syndrome}

\section{Sugata, Y Hoshino, S Naito}

A 48 year old man with valvar abnormalities (thickened mitral leaflet with poor coaptation and severe regurgitation, detected at transoesophageal echocardiography) was diagnosed with primary antiphospholipid syndrome. After aggressive anticoagulation, the diseased mitral valve was successfully replaced with a porcine prosthesis. Examination of the resected posterior leaflet revealed thickened and oedematous leaflet tissue associated with a perivascular mononuclear infiltrate. Immunostaining revealed VCAM-1 expression around the vasculature. These findings suggest that the mononuclear infiltrate and
VCAM-1 expression may have played an important role in the pathogenesis of mitral regurgitation.

(Heart 2000;84:e10www.heartinl.com/cgi/content/full/84/ $5 / \mathrm{e} 10$

\section{Exercise induced supraventricular tachycardia? N P Gall, K Lascelles, $R \mathcal{F}$ Wainwright}

ECGs are susceptible to noise which can make their interpretation difficult. Exercise testing presents particular problems in this regard, hence our reliance on an averaged ECG for diagnosis. On occasion ECG artefacts may be sufficiently organised to render differentiation from a true arrhythmia difficult, with potentially important consequences for patient management. Such a case involving a 59 year old woman who presented with exertional chest pain and palpitations and was referred for exercise testing is described.

(Heart 2000;84:e11) www.heartjnl.com/cgi/content/full/ $84 / 5 / \mathrm{e} 11$ 